\title{
3D-QSAR Analysis and Molecular Docking of Thiosemicarbazone Analogues as a Potent Tyrosinase Inhibitor
}

\author{
Joonho Park and Nack-Do Sung ${ }^{\dagger, *}$ \\ Department of Biology, Queen's University Kingston, ON, K7L-3N6 Canada \\ 'Department of Applied Biological and Chemistry, College of Agriculture \& Life Science, Chungnam National University, \\ Daejeon 305-345, Korea. *E-mail: ndsung15@hanmail.net \\ Received October 8, 2010, Accepted February 14, 2011
}

\begin{abstract}
Three dimensional quantitative structure-activity relationships (3D-QSARs) between new thiosemicarbazone analogues (1-31) as a substrate molecule and their inhibitory activity against tyrosinase as a receptor were performed and discussed quantitatively using CoMFA (comparative molecular field analysis) and CoMSIA (comparative molecular similarity indices analysis) methods. According to the optimized CoMSIA 2 model obtained from the above procedure, inhibitory activities were mainly dependent upon H-bond acceptor favored field (36.5\%) of substrate molecules. The optimized CoMSIA 2 model, with the sensitivity of the perturbation and the prediction, produced by a progressive scrambling analysis was not dependent on chance correlation. From molecular docking studies, it is supposed that the inhibitory activation of the substrate molecules against tyrosinase (PDB code: 1WX2) would not take place via uncompetitive inhibition forming a chelate between copper atoms in the active site of tyrosinase and thiosemicarbazone moieties of the substrate molecules, but via competitive inhibition based on H-bonding.
\end{abstract}

Key Words : 3D-QSAR, CoMFA, CoMSIA, Thiosemicarbazone analogues, Tyrosinase inhibitor, Molecular docking

\section{Introduction}

Tyrosinase (monophenol or $o$-diphenol, oxygen oxido reductase, EC 1.14.18.1) is known to be a multifunctional copper containing an enzyme from the oxidase super family that presents in plants, microorganism and animals. ${ }^{1}$ Tyrosinase is also responsible for the hydroxylation of tyrosine into $o$-quinone via $o$-diphenols and is involved in the formation of pigments such as melanins in mammals. That is, tyrosinase catalyzes the hydroxylation of tyrosine and converts it to L-DOPA (L-3,4-dihydroxyphenyl alanine), which is called monophenolase. L-DOPA is oxidized to Ldopaquinone, which is diphenolase, by Tyrosinase. As a result, these melanogenesis-controlling enzymes are important targets on the processes of skin color control in the research. ${ }^{2}$ The skin and hair color of mammalian are determined by some factors, the most important one is the degree and the distribution of melanin pigmentation. Melanin is secreted by melanocyte cells distributed in the basal layer of the dermis. ${ }^{3}$ In addition, tyrosinase is responsible for the undesired enzymatic browning of fruits and vegetables, ${ }^{4}$ which makes the identification of novel tyrosinase inhibitors extremely important. Therefore, the development and screening of potent inhibitors of phenol oxidase have huge impacts on agriculture, food and cosmetic industry. In recent, the crystallographic structure of tyrosinase has been established, enabling a close look of its three dimensional structure and better understanding of its activation mechanism..$^{5}$ It is revealed that the presence of a hydrophobic protein pocket adjoins the active site of binuclear copper. Tyrosinase has three domains. Its central domain contains the active site of binuclear copper. Six conserved histidine residues bind a pair of copper atoms in the active site of tyrosinase, which interacts with both molecular oxygen and its phenolic substrate molecules. Tyrosinase inhibitors from natural and synthetic sources and the activation mechanism of tyrosinase have been studied widely. ${ }^{6}$

Until now, so many researchers reported and discovered several classes of potent tyrosinase inhibitors. That is, tetraketones as a new class of tyrosinase inhibitors, ${ }^{7}$ naturally occurred tyrosinase inhibitors, ${ }^{8}$ critical review of promising novel inhibitors from synthetic origins, ${ }^{9}$ heterocyclic compounds against the enzyme tyrosinase essential for melanin production, ${ }^{10}$ thiosemicarbazides as tyrosinase and phenoloxidase inhibitors, ${ }^{11}$ QSAR studies of mushroom tyrosinase inhibitors, ${ }^{12}$ inhibitory effect of 6-(3-hydroxyphenyl)-2-naphthol on tyrosinase activity, ${ }^{13}$ identification of an alkylhydroquinone from Rhus succedanea, ${ }^{14}$ and skin-whitening effect of an aqueous extract from Salicornia herbacea ${ }^{15}$ etc. were evaluated and studied. However, HQSAR analyses on the melanogenesis inhibitory activities of alkyl-3,4-dihydroxylbenzoates, ${ }^{16}$ QSAR between the inhibition activity of tyrosinephosphate $1 \mathrm{~B}$ and oleanolic acids, ${ }^{17}$ CoMFA analysis on PTP-1B activity of 3 $\beta$-hydroxy-12-oleanen-28-oic acids and the prediction of active compounds ${ }^{18}$ were reported by the author. The complex of tyrosinase and 1-(1-arylethylidene)thiosemicarbazones, and a possible mechanism for their anti-tyrosinase activity proposed the ability to chelate with the two copper atoms in the active site of tyrosinase. This ability is necessary for the catalytic activity of tyrosinase. ${ }^{11 \mathrm{~d}}$ 
While forming a chelate between binuclear copper atoms of tyrosinase and thiosemicarbazone analogues (1-31) as the substrate molecule, to make sure uncompetitive inhibition, and to search a new material of superior melanogenesis inhibitory activity, 3D-QSAR (CoMFA and CoMSIA) between structures of the substrate molecules and their tyrosinase inhibitory activity, and molecular docking were performed and discussed quantitatively. 3D-QSARs methods ${ }^{19}$ will minimize the number of compounds that synthetic chemists should prepare and the time needed to discover new candidates. Actually, the correlation between physicochemical properties and biological activity is a useful tool for the design of new compounds.

\section{Materials and Methods}

Molecular Alignment and Modeling. In the new search for the most potent compounds, the data set on the tyrosinase inhibitory activity of thiosemicarbazone analogues (1-(1arylethylidene)thiosemicarbazones; 1-14 and 4-aryloxymethylidenethiosemicarbazones; 15-31) as the substrate molecule used for the CoMFA ${ }^{19 b}$ and CoMSIA $^{19 c}$ analysis was taken from literatures. ${ }^{11 \mathrm{~d}, 11 \mathrm{e}}$ Following the same procedures, ${ }^{21} 3 \mathrm{D}-\mathrm{QSAR}$ analyses were performed using the CoMFA and CoMSIA module within the Sybyl package (Ver. 8.1, Tripos Inc.). ${ }^{20}$ The refined binding conformation of compound (1) was used for the 3D-QSAR studies. The most stable form, in which the energy of central molecule is the lowest, was investigated using simulated annealing method. ${ }^{22}$ The atom-based fit and field fit alignment methods were applied using a stable hydrogen-removed form (2-ethylidenehydrazinecarbothioamide) as a template. A common substructurebased alignment was adopted. It attempted to align molecules to the template molecule on a common backbone. For example, according to least-squares atom-based fit, alignments of the potential energy minimized structures of substrate molecules are shown in Figure 1. The CoMFA and CoMSIA model were obtained from training set compounds $(\mathrm{n}=23)$ without test set $(\mathrm{n}=8)$ in data set compounds $(\mathrm{n}=$

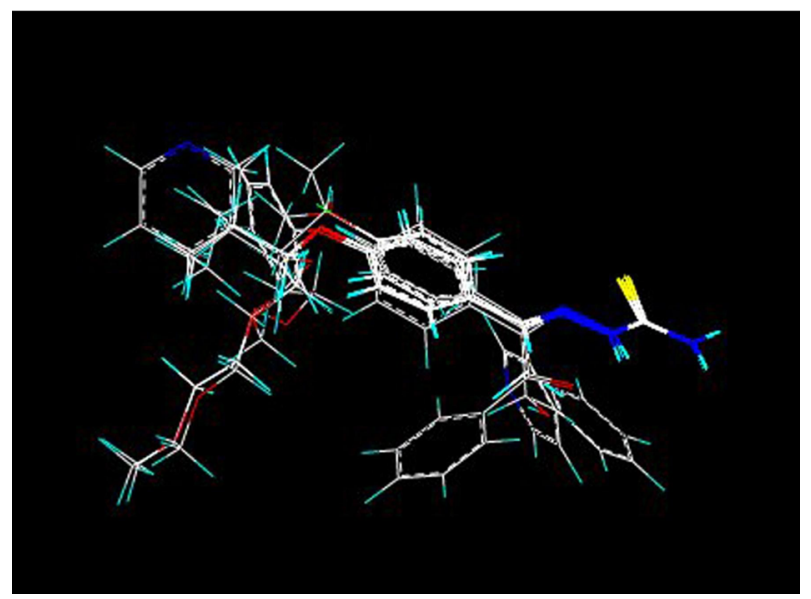

Figure 1. Alignment of the superimposed image of thiosemicarbazone analogues (1-31) according to a least-squares atom based fit.
31). And, the predictability of these two models was evaluated using test set compounds. To analyze visually the structural characteristics of substrate molecules, characteristic fields with the optimized model are shown in capped sticks of the most potent compound (8) as contour maps of three dimensional space. And, the ratio (\%) of favor versus disfavor was 80:20.

PLS and Scrambling Analysis. The 3D-QSAR between descriptors on structural characteristics of aligned compounds in three dimensional space and their tyrosinase inhibition activity $\left(O b s . p I_{50}\right)$ were analyzed by PLS (partial least squared) method. ${ }^{23}$ The number of components via LOO (leave-one-out) cross-validation process from PLS analysis was determined. Final PLS analyzed the model that was derived from an on cross-validation process using the optimal number of components. The predictive residual sums of squares (PRESS) values were calculated from the results of the cross-validation which is confirmed by the predictability of derived models. The model quality was determined as such: no less than $\mathrm{R}_{\text {ncv. }}^{2}=0.9$ of an on cross-validated. $\mathrm{R}^{2}$ ncv. was considered to be a good fit and a cross-validated $\mathrm{R}_{\mathrm{cv} \text {. }}^{2}$ (or $\left.\mathrm{q}^{2}\right)>0.5$ normally indicates a significant predictability. In addition, to evaluate the sensitivity of chance correlations of 3D-QSAR models, a progressive scrambling procedure (maximum: 4 bins, minimum: 2 bins and critical point: 0.85 ) was applied to the $3 \mathrm{D}-\mathrm{QSAR}$ models. ${ }^{24}$ The progressive scrambling with 2-5 components of inhibitory activation data produces three statistical data; the predictivity $\left(\mathrm{q}^{2}\right)$ of the model, the calculated cross-validated standard error of prediction (cSDEP) and the sensitivity of perturbation $\left(\mathrm{d}_{\mathrm{q}}{ }^{2} /\right.$ $\left.\mathrm{dr}^{2} \mathrm{yy}^{\prime}\right)$, respectively.

Molecular Docking. The flexible docking method, called Surflex-Dock program (Sybyl. Ver. 8.1.1), ${ }^{20}$ uses an incremental construction algorithm to place substrate ligands in the active site of tyrosine as a receptor. X-ray crystallographic structure of tyrosinase was found from RCSB protein data bank (PDB entry code: $1 \mathrm{WX} 2) .{ }^{5,25}$ All water molecules and Caddie protein (ORF378) in tyrosinase were stripped and hydrogen atoms were generated from standard geometry. And the two copper ions in the active site were always kept in a protein description. The automated molecular docking calculations were carried out through SurflexDock program. The score of Surflex-Dock uses the scoring function that is induced experimentally based on binding affinity $(\mathrm{Kd})$ of protein-ligand complex and X-ray crystal structure. ${ }^{26}$ The binding characteristics with amino residues and substrates are hydrophobic, polar, repulsive, entropic, solvation and crash. ${ }^{27}$ Here, the crash score is the degree of in appropriate penetration of ligand into a protein as well as the degree of internal self-clashing. The scores which are close to 0.0 are favorable. And a polar contribution is the amount of total affinity score that is due to polar interactions.

\section{Results and Discussion}

3D-QSAR Models. To produce 3D-QSAR (CoMFA and CoMSIA) models which can effectively explain the results 
Table 1. Observed inhibition activity $\left(\mathrm{Obs} \cdot \mathrm{pI}_{50}\right)$ of thiosemicarbazones against tyrosinase and predicted inhibition activity $\left(\right.$ Pred.pI $\left.\mathrm{I}_{50}\right)$ by the CoMSIA models for training set

\begin{tabular}{|c|c|c|c|c|c|c|c|}
\hline \multirow{2}{*}{ No. } & \multicolumn{2}{|c|}{ Substituents (R) } & \multirow{2}{*}{$O b s \cdot \mathrm{pI}_{50}$} & \multicolumn{2}{|c|}{ CoMSIA 1} & \multicolumn{2}{|c|}{ CoMSIA $2^{c}$} \\
\hline & 1 & 2 & & Pred.pI ${ }_{50}^{a}$ & $\Delta \mathrm{pI}_{50}{ }^{b}$ & Pred.pI ${ }_{50}{ }^{a}$ & $\Delta \mathrm{pI}_{50}{ }^{b}$ \\
\hline 3 & 4-(OH)ph- & $\mathrm{CH}_{3}-$ & 5.83 & 5.84 & -0.01 & 5.98 & -0.15 \\
\hline 4 & $2,4,6-(\mathrm{OH})_{3} \mathrm{ph}-$ & $\mathrm{CH}_{3^{-}}$ & 4.04 & 4.33 & -0.29 & 4.01 & 0.03 \\
\hline 5 & 4-(F)ph- & $\mathrm{CH}_{3}-$ & 6.09 & 5.90 & 0.19 & 5.99 & 0.10 \\
\hline 7 & $4-\left(\left(\mathrm{CH}_{3}\right)_{2} \mathrm{CH}\right) \mathrm{ph}-$ & $\mathrm{CH}_{3}-$ & 5.37 & 5.19 & 0.18 & 5.39 & -0.02 \\
\hline 8 & 4- $\left(\mathrm{CH}_{3} \mathrm{O}\right) \mathrm{ph}-$ & $\mathrm{CH}_{3}-$ & 6.31 & 6.21 & 0.10 & 6.13 & 0.18 \\
\hline 10 & 3-pyridinyl & $\mathrm{CH}_{3}-$ & 5.37 & 5.26 & 0.11 & 5.68 & -0.31 \\
\hline 11 & 4- $\left(\mathrm{CH}_{3} \mathrm{O}\right) \mathrm{phCH}_{2}-$ & $\mathrm{CH}_{3-}$ & 5.75 & 5.84 & -0.09 & 5.56 & 0.19 \\
\hline 12 & $2-(4-\mathrm{HOph})\left(\mathrm{CH}_{2}\right)_{2-}$ & $\mathrm{CH}_{3-}-$ & 5.64 & 5.85 & -0.21 & 5.66 & -0.02 \\
\hline 13 & $\mathrm{Ph}-$ & 4-(OH) $\mathrm{phCH}_{2-}$ & 3.71 & 3.51 & 0.20 & 3.62 & 0.09 \\
\hline 14 & $\mathrm{Ph}-$ & Benzoyl & 3.45 & 3.45 & 0.00 & 3.44 & 0.01 \\
\hline 15 & 4-( $\left(\mathrm{HOCH}_{2} \mathrm{CH}_{2} \mathrm{O}\right)$ ph- & $\mathrm{H}-$ & 5.65 & 5.43 & 0.22 & 5.51 & 0.14 \\
\hline 16 & 4- $\left(\mathrm{CH}_{3}\left(\mathrm{CH}_{2}\right)_{3} \mathrm{O}\left(\mathrm{CH}_{2}\right)_{2} \mathrm{O}\right)$ ph- & $\mathrm{H}-$ & 5.51 & 5.63 & -0.12 & 5.55 & -0.04 \\
\hline 17 & 4- $\left(\mathrm{CH}_{3} \mathrm{O}\left(\mathrm{CH}_{2}\right)_{2} \mathrm{O}\left(\mathrm{CH}_{2}\right)_{2} \mathrm{O}\right)$ ph- & $\mathrm{H}-$ & 5.94 & 5.85 & 0.09 & 5.83 & 0.11 \\
\hline 18 & 4- $\left(\mathrm{CH}_{3} \mathrm{O}\left(\mathrm{CH}_{2}\right)_{4} \mathrm{O}\right)$ ph- & $\mathrm{H}-$ & 5.84 & 5.93 & -0.09 & 5.80 & 0.04 \\
\hline 19 & 4- $\left(\mathrm{CH}_{3} \mathrm{OCH}_{2} \mathrm{CH}_{2} \mathrm{O}\right)$ ph- & $\mathrm{H}-$ & 5.53 & 5.57 & -0.04 & 5.53 & 0.00 \\
\hline 20 & 4- $\left(\mathrm{OHCH}_{2} \mathrm{CH}_{2} \mathrm{OCH}_{2} \mathrm{O}\right)$ ph- & $\mathrm{H}-$ & 5.86 & 5.60 & 0.26 & 5.78 & 0.08 \\
\hline 24 & 4-((CH$\left.)_{2} \mathrm{CHO}\right) \mathrm{ph}-$ & $\mathrm{H}-$ & 5.42 & 5.44 & -0.02 & 5.35 & 0.08 \\
\hline 25 & 4- $\left(\mathrm{CH}_{3}\left(\mathrm{CH}_{2}\right)_{2} \mathrm{O}\right) \mathrm{ph}-$ & $\mathrm{H}-$ & 4.89 & 5.27 & -0.38 & 5.27 & -0.38 \\
\hline 26 & 4- $\left(\mathrm{CH}_{2}=\mathrm{CHCH}_{2} \mathrm{O}\right) \mathrm{ph}-$ & $\mathrm{H}-$ & 5.26 & 5.25 & 0.01 & 5.26 & 0.00 \\
\hline 27 & 4- $\left(\left(\mathrm{CH}_{3}\right)_{2} \mathrm{CHCH}_{2} \mathrm{O}\right) \mathrm{ph}-$ & $\mathrm{H}-$ & 5.06 & 5.29 & -0.23 & 5.29 & -0.23 \\
\hline 28 & 4- $\left(\mathrm{CH}_{3}\left(\mathrm{CH}_{2}\right)_{4} \mathrm{O}\right) \mathrm{ph}-$ & $\mathrm{H}-$ & 5.39 & 5.33 & 0.06 & 5.33 & 0.06 \\
\hline 30 & 4- $\left(\mathrm{C}_{6} \mathrm{H}_{5} \mathrm{O}\right) \mathrm{ph}-$ & $\mathrm{H}-$ & 5.44 & 5.34 & 0.10 & 5.34 & 0.10 \\
\hline 31 & 4-((4-F)phO)ph- & $\mathrm{H}-$ & 5.30 & 5.36 & -0.06 & 5.36 & -0.06 \\
\hline 32 & Kojic acid & - & $3.93^{d}$ & - & - & - & - \\
\hline
\end{tabular}

${ }^{a}$ Predicted values by the model. ${ }^{b}$ difference of observed $\left(O b s . p I_{50}\right)$ values and predicted (Pred.pI $\left.I_{50}\right)$ values. ${ }^{c}$ optimized model. ${ }^{d}$ convert IC $\mathrm{I}_{50}$ values into $\mathrm{pI}_{50}\left(\mathrm{IC}_{50}: 16.67 \mathrm{uM}\right)$.

Table 2. Summary of the statistical parameters of 3D-QSAR models with two alignments

\begin{tabular}{lccccccc}
\hline \multirow{2}{*}{ Models No. } & \multirow{2}{*}{ Alignments } & \multicolumn{5}{c}{ PLS Analyses } \\
\cline { 3 - 8 } & & Grid $(\AA)$ & $\mathrm{CN}$ & $\mathrm{r}_{\text {cv. }}{ }^{a}$ & $\mathrm{r}^{2}{ }_{\text {ncv. }}{ }^{b}$ & SE $_{\text {ncv. }}{ }^{c}$ & $\mathrm{~F}$ \\
\hline CoMFA 1 & $\mathrm{AF}^{d}$ & 2.5 & 3 & 0.509 & 0.923 & 0.213 & 76.146 \\
CoMFA 2 & $\mathrm{FF}^{e}$ & 2.0 & 3 & 0.349 & 0.921 & 0.217 & 73.649 \\
CoMSIA 1 & $\mathrm{AF}^{d}(\alpha=0.3)$ & 2.5 & 3 & 0.622 & 0.944 & 0.182 & 107.501 \\
CoMSIA 2 & $\mathrm{FF}^{e}(\alpha=0.3)$ & 2.0 & 3 & 0.504 & 0.958 & 0.157 & 146.149 \\
\hline
\end{tabular}

Notes: F; fraction of explained versus unexplained variance, $\mathrm{CN}$; number of major component, attenuation factor; $\alpha$. ${ }^{a}$ cross-validated ${ }^{2}$. ${ }^{b}$ non-crossvalidated $\mathrm{r}^{2}$. ${ }^{c}$ standard error estimate. ${ }^{d}$ atomic based fit. ${ }^{e}$ field fit. ${ }^{f}$ optimized model.

of PLS analysis, the CoMFA model is derived from the combined conditions of 3 characteristic fields; the steric field (S), electrostatic field (E) and hydrophobic field ( $\mathrm{Hy})^{19 \mathrm{~b}}$ as an additional field, while CoMSIA model is derived from the combined conditions of 5 characteristic fields; steric field (S), electrostatic field (E), hydrophobic field (Hy), hydrogen bond donor field (HD) and hydrogen bond acceptor field (HA). The observed inhibitory activities $\left(O b s \cdot \mathrm{pI}_{50}\right)$ of the substrate molecules $\left(\mathrm{R}_{1} \& \mathrm{R}_{2}\right)$ against tyrosinase, the predicted inhibitory activities (Pred.pI ${ }_{50}$ ) by $3 \mathrm{D}-\mathrm{QSAR}$ model and the differences $\left(\mathrm{pI}_{50}\right)$ between these two values were summarized in Table 1 . The $\mathrm{R}_{1}=$ phenyl, $\mathrm{R}_{2}=$ benzoyl substituent (14) showed the lowest inhibition activity, but the $\mathrm{R}_{1}=4$-methoxyphenyl, $\mathrm{R}_{2}=\mathrm{CH}_{3}$ substituent (8) showed the highest inhibitory activity. The results of PLS analysis of 4 CoMFA and CoMSIA models which represented the best statistic values among models are summarized in Table 2. The models were derived from a major component number (3), a grid (1.0-3.0 $\AA$ ) and under the conditions of different alignment (AF \& FF). CoMSIA models were more significant 
Table 3. Observed inhibition activity $\left(O b s \cdot \mathrm{pI}_{50}\right)$ of thiosemicarbazones against tyrosinase and predicted inhibition activity $\left(\right.$ Pred.pI $\left.{ }_{50}\right)$ by the optimized CoMSIA models for the test set

\begin{tabular}{|c|c|c|c|c|c|c|c|}
\hline \multirow{2}{*}{ No. } & \multicolumn{2}{|l|}{ Substituents (R) } & \multirow{2}{*}{ Obs.pI $\mathrm{I}_{50}$} & \multicolumn{2}{|c|}{ CoMSIA 1} & \multicolumn{2}{|c|}{ CoMSIA $2^{c}$} \\
\hline & 1 & 2 & & Pred.pI ${ }_{50}{ }^{a}$ & $\Delta \mathrm{pI}_{50}{ }^{b}$ & Pred.pI ${ }_{50}{ }^{a}$ & $\Delta \mathrm{pI}_{50}{ }^{b}$ \\
\hline 1 & $\mathrm{H}-$ & $\mathrm{CH}_{3}-$ & 5.75 & 5.82 & -0.07 & 5.73 & 0.02 \\
\hline 2 & 4-( $\left(\mathrm{CH}_{3}\right) \mathrm{ph}-$ & $\mathrm{CH}_{3-}^{-}$ & 5.89 & 5.85 & 0.04 & 5.73 & 0.16 \\
\hline 6 & 4-(Br)ph- & $\mathrm{CH}_{3-}$ & 5.72 & 5.77 & -0.05 & 5.85 & -0.13 \\
\hline 9 & 2-pyrazinyl & $\mathrm{CH}_{3^{-}}$ & 5.35 & 5.25 & 0.10 & 5.55 & -0.20 \\
\hline 21 & 4-(( $\left.\left(\mathrm{CH}_{2} \mathrm{OH}\right)_{2} \mathrm{CHOCH}_{2} \mathrm{O}\right)$ ph- & $\mathrm{H}-$ & 5.50 & 5.73 & -0.23 & 6.05 & -0.55 \\
\hline 22 & 4-(3-pyridylCH$\left.{ }_{2} \mathrm{O}\right)$ ph- & $\mathrm{H}-$ & 4.94 & 5.22 & -0.28 & 5.29 & -0.35 \\
\hline 23 & 4- $\left(\mathrm{CH}_{3} \mathrm{CH}_{2} \mathrm{O}\right) \mathrm{ph}-$ & $\mathrm{H}-$ & 5.07 & 5.42 & -0.35 & 5.05 & 0.02 \\
\hline 28 & 4- $\left(\mathrm{CH}_{3}\left(\mathrm{CH}_{2}\right)_{3} \mathrm{O}\right)$ ph- & $\mathrm{H}-$ & 5.28 & 5.29 & -0.01 & 5.67 & -0.39 \\
\hline
\end{tabular}

${ }^{a}$ The values were calculated according to the optimized models in Table $1 .{ }^{b}$ difference between observed $\left(\right.$ Obs.pI $\left.I_{50}\right)$ values and predicted $\left(\right.$ Pred.pI $\left.5_{50}\right)$ values. ${ }^{c}$ optimized model.

Table 4. Model stability test for the CoMSIA models by progressive scrambling

\begin{tabular}{cccccccc}
\hline \multirow{2}{*}{$\mathrm{NC}^{a}$} & \multicolumn{3}{c}{ CoMSIA 1} & & \multicolumn{3}{c}{$\operatorname{CoMSIA~2~}^{e}$} \\
\cline { 2 - 3 } \cline { 5 - 7 } & $\mathrm{q}^{2 b}$ & $\operatorname{cSDEP}^{c}$ & $\mathrm{~d}_{\mathrm{q}}{ }^{2} / \mathrm{dr}^{2}{ }_{\mathrm{yy}}{ }^{d}$ & & $\mathrm{q}^{2 b}$ & $\operatorname{cSDEP}^{c}$ & $\mathrm{~d}_{\mathrm{q}}{ }^{2} / \mathrm{dr}^{2}{ }_{\mathrm{yy}}{ }^{d}$ \\
\hline 2 & 0.335 & 0.607 & 1.135 & & 0.230 & 0.657 & 0.945 \\
$3^{e}$ & 0.385 & 0.598 & 1.281 & & 0.330 & 0.628 & 1.090 \\
4 & 0.342 & 0.637 & 1.195 & & 0.341 & 0.640 & 1.215 \\
5 & 0.331 & 0.662 & 1.197 & 0.305 & 0.677 & 1.295 \\
\hline
\end{tabular}

${ }^{a}$ Number of component. ${ }^{b}$ predictability of the model $\mathrm{q}^{2}=1-(\mathrm{cSDEP})^{2}$ ${ }^{c}$ calculated cross-validated standard error of prediction. ${ }^{d}$ slope of $\mathrm{q}^{2}$ (cross-validated correlation coefficient from Sybyl, seed No. 3043). ${ }^{e}$ optimized model.

than CoMFA models and there were no remarkable differences of statistic values between the models. For the predictability of the CoMSIA 2 model, test set compounds were confirmed in Table 3 . In order to draw a high correlativity model, the compounds out of the linearity, which explains the relation between observed values and predicted values, were selected. But the CoMSIA 1 model should be applicable to the prediction of higher potent molecules with the inhibitory activities against tyrosinase. Therefore, the CoMSIA 1 and CoMSIA 2 model had a good statistical quality.

Progressive Scrambling. From the results of Table 2, in order to evaluate the sensitivity of chance correlations on the CoMSIA 1 and CoMSIA 2 models, the LOO cross-validation and progressive scrambling analyses were performed with 2-5 components. ${ }^{24}$ The perturbation prediction $\left(\mathrm{q}^{2}\right)$, cSDEP as the function of correlation coefficient between true values (y) and perturbed values ( $\left.y^{\prime}\right)$ of dependent variables, and the slope of $\mathrm{q}^{2}$ (cross-validated correlation coefficient) with respect to the correlation between original dependent variables and perturbed dependent variables $\left(\mathrm{d}_{\mathrm{q}}{ }^{2} /\right.$ $\left.\mathrm{dr}^{2} \mathrm{yy}^{\prime}\right)$ are summarized in Table 4. The data suggested that three components were optimal because a $\mathrm{d}_{\mathrm{q}}{ }^{2} / \mathrm{dr}^{2} \mathrm{yy}^{2}$ slope near unity (0.80-1.20) as the sensitivity of perturbations should be optimal. ${ }^{28}$ In case of three components in the CoMSIA 2 model, it is revealed that the sensitivity of perturbation $\mathrm{d}_{\mathrm{q}}{ }^{2} / \mathrm{dr}^{2}{ }_{\mathrm{yy}}^{\prime}=1.090$ and prediction $\mathrm{q}^{2}=0.330$ were not dependent on chance correlation. But the CoMSIA 2 model showed low predictability. Consequently, the best one is the CoMSIA 2 model as the most optimized model.

Optimized CoMSIA 2 Model. In addition, Table 5 represents contribution ratios (\%) of CoMFA and CoMSIA fields, errors, average residuals (Ave.) and PRESS for training set and test set. The contribution ratios (\%) of CoMSIA fields in the optimized CoMSIA 2 model regarding inhibitory activities are as follows: hydrophobic field $(21.5 \%)$, electrostatic field $(21.3 \%)$, steric field (14.0\%) and H-bond acceptor field (36.5\%) field. Therefore, the inhibitory activities against tyrosinase were dependent upon hydrophobic, electrostatic and $\mathrm{H}$-bond acceptor factors of $\mathrm{R}_{1}$ and $\mathrm{R}_{2}$ group in substrate molecules. From the error values, the average residuals (Ave.) and PRESS of these two models, the error values of training set were lower than those of test set. Therefore, the fact that correlativity is better than predictability from the errors in Table 5 shows the statistical quality of the optimized CoMSIA 2 model. From the relationships between observed inhibition activities $\left(O b s . p I_{50}\right)$ against tyrosinase

Table 5. Summary of field contribution, Ave. and PRESS of 3D-QSAR models

\begin{tabular}{|c|c|c|c|c|c|c|c|c|c|}
\hline \multirow{2}{*}{ Model No. } & \multicolumn{5}{|c|}{ Field Contribution (\%) } & \multicolumn{2}{|c|}{ Training set } & \multicolumn{2}{|c|}{ Test set } \\
\hline & $\mathrm{S}$ & $\mathrm{E}$ & Hy & HD & HA & Ave. & PRESS & Ave. & PRESS \\
\hline CoMFA 1 & 61.2 & 35.3 & 3.5 & - & - & 0.15 & 0.867 & 0.25 & 0.633 \\
\hline CoMFA 2 & 55.6 & 36.2 & 8.3 & - & - & 0.15 & 0.893 & 0.55 & 3.912 \\
\hline CoMSIA 1 & 17.7 & 13.8 & 26.7 & 5.0 & 36.8 & 0.13 & 0.627 & 0.14 & 0.273 \\
\hline CoMSIA $2^{a}$ & 14.0 & 21.3 & 21.5 & 6.6 & 36.5 & 0.11 & 0.468 & 0.23 & 0.660 \\
\hline
\end{tabular}

Notes: S; steric, E; electrostatic, Hy; hydrophobic, HD; H-bond donor, HA; H-bond Acceptor., Ave.; average residual, PRESS; predictive residual sum of squares. ${ }^{a}$ optimized model. 


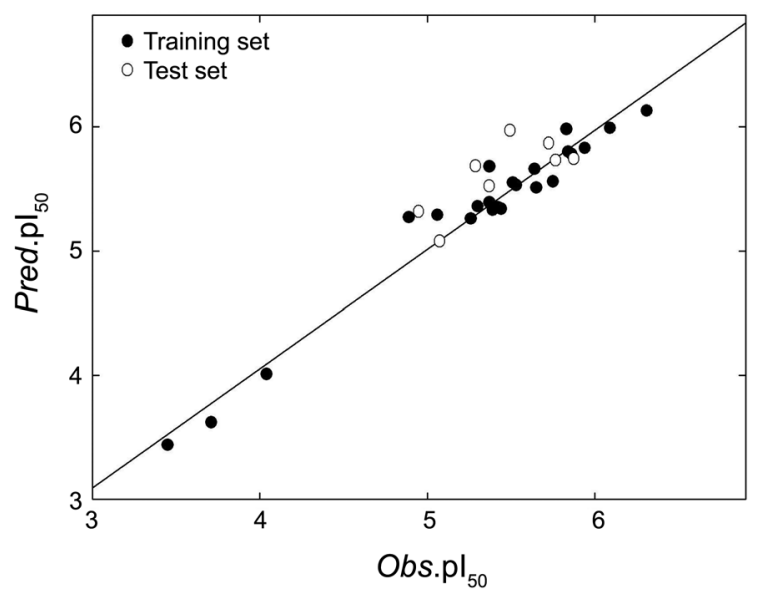

Figure 2. Relationships between observed inhibition activity $\left(O b s . \mathrm{pI}_{50}\right)$ against tyrosinase and predicted inhibition activity (Pred.pI ${ }_{50}$ ) by the optimized CoMSIA 2 model (For training set:; Pred. $\mathrm{pI}_{50}=0.960 O b s . \mathrm{pI}_{50}+0.215, \mathrm{n}=23, \mathrm{~S}=0.146, \mathrm{~F}=485.073$, $\left.\& \mathrm{q}^{2}=0.956, \mathrm{r}^{2}=0.960\right)$.

and predicted inhibition activities (Pred. $\mathrm{pI}_{50}$ ) by the optimized CoMSIA 2 model as shown in Figure 2, the first order equation for training set was obtained as follows: for training set (Pred.pI $\mathrm{I}_{50}=0.960$ Obs.pI $\mathrm{I}_{50}+0.215, \mathrm{n}=23, \mathrm{~S}=0.146, \mathrm{~F}$ $\left.=485.073 \& \mathrm{q}^{2}=0.956, \mathrm{r}^{2}=0.960\right)$. The error of test set had a low predictability as we expected in Figure 2.

Contour Maps Analysis. To analyze visually the structural characteristics of substrate molecules and the level of contribution of molecular interaction fields related to the optimized CoMSIA 2 model, Figure 3 shows the contour maps of steric field and electrostatic field (Left; front view \& Right; side view). On the phenyl ring of $\mathrm{R}_{1}$-group, a steric bulky group (green) at the meta- and para-position makes the inhibitory activity increase and sterically less bulky group (yellow) at the ortho-position does it so. In addition, negative charge favored group (red) at the para-position and positive charge favored group (blue) at the meta-position are expected to increase the inhibitory activity. On the other

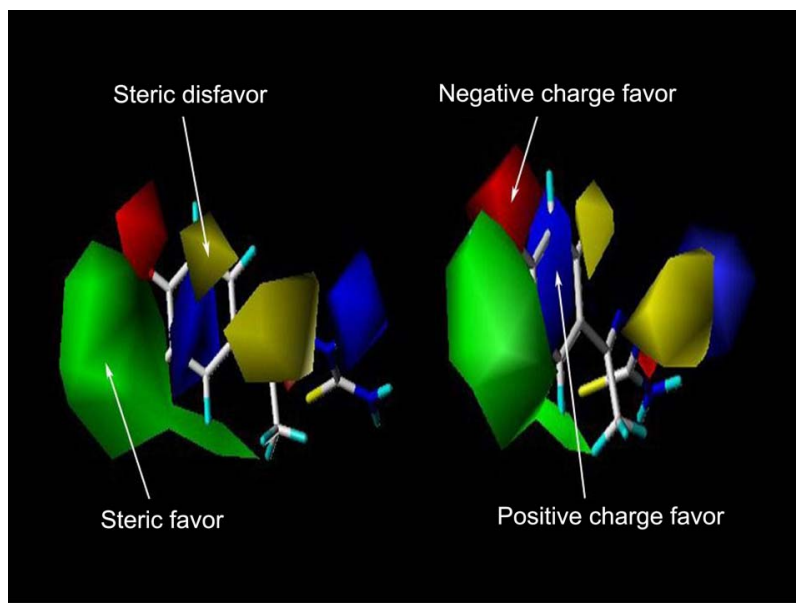

Figure 3. The contour maps for the steric (green; favor) and electrostatic (blue; favor) field by the CoMSIA 2 model. The most potent compounds $(8)$ is shown in capped sticks. (favor: disfavor $=$ 80:20\%), (Left: Front view \& Right: Side view).

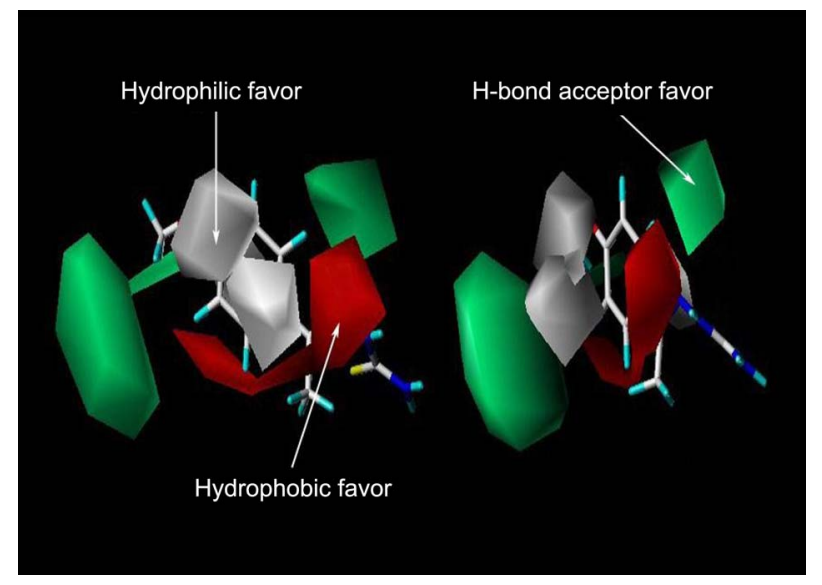

Figure 4. The contour maps for the hydrophobic (red; favor) and $\mathrm{H}$-bond acceptor (green; favor) field by the CoMSIA 2 model. The most potent compounds (8) is shown in capped sticks. (favor: disfavor $=80: 20 \%)($ Left: Front view \& Right: Side view $)$.

hand, Figure 4 shows the HINT map of hydrophilic favor fields (gray), hydrophobic fields (red), and H-bond field of $\mathrm{H}-$ bond acceptor favor field (green), respectively. On the $\mathrm{R}_{2}-$ group, the hydrophobic group at the ortho- and metaposition and the hydrophilic group at the para-position are expected to increase the inhibitory activity. Especially, it is expected that H-bond acceptor favored group at the meta$\left(\mathrm{C}_{3}\right)$ and ortho- $\left(\mathrm{C}_{6}\right)$ position influences the most to increase the inhibitory activity because its contribution ratio of molecular interaction fields is the biggest. As has been mentioned, inhibitory activities against tyrosinase were mainly dependent upon $\mathrm{H}$-bond acceptor factors of $\mathrm{R}_{1}$ and $\mathrm{R}_{2}$ group. Therefore, the contour maps with the level of contribution of molecular interaction fields related to the optimized CoMSIA 2 model should be relevant to the prediction of the most potent molecules for the inhibitory activity against tyrosinase. Based on these findings, the substituents $\left(\mathrm{R}_{1}\right.$ \& $\mathrm{R}_{2}$ ), which were in accord with CoMSIA fields, will be able to be used effectively for the design of potent inhibitors.

Docking Score and Hydrophobicity. To understand interactions between substrate molecules and the active site of tyrosinase, the molecular dockings of thiosemicarbazone analogues (1-31) as substrate molecules with the active site of oxy-form tyrosinase were performed. The effects of substrate molecules on the tyrosinase activity were examined. Amino acids in the binding site of tyrosinase, related to a protocol algorithm, are composed of 11 polar amino acids, 16 hydrophobic amino acids and two copper atoms. The nature of the active site of tyrosinase is hydrophobic. There are covalent bonds between copper atoms and three histidine residues of nitrogen atoms. That is, $\mathrm{Cu}^{\mathrm{A}}$ binds with $\mathrm{His} 38$, His53, His63 and $\mathrm{Cu}^{\mathrm{B}}$ binds with His 190, His194 and His216, respectively. ${ }^{5}$ According to literatures, kojic acid as a typical tyrosinase inhibitor is known to inhibit melanin production while forming a chelate with two copper atoms (uncompetitive inhibition on tyrosinase). ${ }^{29}$ In case of azelaic acid, inhibiting a melanin production is due to H-binding between substrate molecules and amino acid residues in the 
Table 6. Hydrophobicity of thiosemicarbazones and their docking results to tyrosinase (PDB ID: 1WX2)

\begin{tabular}{|c|c|c|c|c|c|c|}
\hline No. & $\mathrm{Clog} \mathrm{P}^{a}$ & DS & Crash & Polar & Distance $(\AA)^{b}$ & H-bonding sites \\
\hline 1 & 2.401 & 4.54 & -0.38 & 2.80 & 4.87 & Glu182, Asn191 \\
\hline 2 & 2.900 & 5.92 & -1.02 & 2.25 & 3.42 & Per404, His194, Thr203, Ser206 \\
\hline 3 & 2.264 & 4.94 & -0.77 & 1.85 & 4.44 & Thr203, Ser206, His $194^{c}$ \\
\hline 4 & 1.137 & 4.45 & -0.74 & 3.31 & 3.97 & Per404, Asn191, Thr203, Ser206 \\
\hline 5 & 2.628 & 4.59 & -0.34 & 3.02 & 4.55 & Glu182, Asn191 \\
\hline 6 & 3.348 & 4.42 & -0.56 & 2.84 & 4.56 & Glu182, Asn191 \\
\hline 7 & 3.828 & 7.14 & -1.16 & 2.22 & 3.46 & Per404, His194, Thr203, Ser206 \\
\hline 8 & 2.621 & 6.49 & -1.28 & 3.90 & 4.04 & Per404, Arg55, Thr203, Ser206 \\
\hline 9 & 0.380 & 5.72 & -0.94 & 2.68 & 3.78 & Glu182, Asn191, His194 ${ }^{c}$ \\
\hline 10 & 1.324 & 5.19 & -0.57 & 3.08 & 4.60 & Glu182, Asn191 \\
\hline 11 & 2.919 & 6.36 & -1.52 & 2.06 & 4.86 & Glu182, Asn191 \\
\hline 12 & 2.162 & 6.96 & -0.92 & 3.46 & 4.41 & Glu182, Asn191,Thr203, Ser206, His194 ${ }^{c}$ \\
\hline 13 & 3.128 & 5.99 & -1.23 & 3.36 & 4.50 & Glu182, Asn191, Met201 \\
\hline 14 & 3.673 & 3.51 & -1.34 & 2.71 & 5.48 & Glu182, Asn191 \\
\hline 15 & 1.047 & 5.17 & -1.20 & 4.31 & 4.58 & Ile42, Arg55, Gly204, Ser206 \\
\hline 16 & 3.257 & 5.32 & -1.77 & 2.70 & 5.70 & Ile42, Arg55 \\
\hline 17 & 1.674 & 5.39 & -1.60 & 2.24 & 4.99 & Arg55, Asn191 \\
\hline 18 & 2.236 & 4.91 & -1.23 & 1.02 & 4.05 & Met201, Thr203 \\
\hline 19 & 1.810 & 5.21 & -1.31 & 2.11 & 4.03 & Asn191, Ala202, Thr203 \\
\hline 20 & 1.128 & 6.33 & -1.09 & 4.13 & 4.13 & Arg55, Met201 \\
\hline 21 & 1.006 & 5.96 & -1.08 & 3.72 & 4.86 & Arg55, Asn191, Met201 \\
\hline 22 & 2.191 & 5.77 & -1.17 & 2.50 & 4.42 & Arg55, His $194^{c}$ \\
\hline 23 & 2.449 & 4.07 & -0.88 & 3.06 & 4.12 & Glu182, Asn191 \\
\hline 24 & 2.758 & 4.66 & -1.11 & 2.74 & 3.81 & Glu182, Asn191 \\
\hline 25 & 2.978 & 5.00 & -1.00 & 3.16 & 4.22 & Glu182, Asn191 \\
\hline 26 & 2.694 & 4.46 & -1.00 & 2.85 & 4.41 & Glu182, Asn191 \\
\hline 27 & 3.377 & 4.93 & -0.98 & 2.98 & 4.63 & Glu182, Asn191 \\
\hline 28 & 3.507 & 5.36 & -0.88 & 2.82 & 4.70 & Glu182, Asn191 \\
\hline 29 & 4.036 & 4.94 & -1.05 & 2.74 & 3.87 & Glu182, Asn191 \\
\hline 30 & 3.963 & 4.54 & -0.80 & 1.63 & 3.52 & Met201, Thr203 \\
\hline 31 & 4.106 & 4.45 & -0.86 & 2.73 & 4.26 & Glu182, Asn191 \\
\hline $32^{d}$ & -1.387 & 4.67 & -0.37 & 2.08 & 2.97 & Per404, Arg192, Ser206 \\
\hline
\end{tabular}

${ }^{a}$ Hydrophobicity of calculated whole molecule. ${ }^{b}$ spatial distance between hetero atoms in substrate and copper atoms in tyrosinase. ${ }^{c} \mathrm{Pi}-\mathrm{Pi}$ stacking site. ${ }^{d}$ kojic acid; copper chelating.

active site of tyrosinase (competitive inhibition). ${ }^{30}$ Many substrate molecules showed that the two H-bonds were consisted of amino acid residues Glu182 and Asn191 in the active site of tyrosinase.

In addition, the calculated hydrophobicity (ClogP), docking scores, crash, polar, spatial distances and H-bonding sites were summarized in Table 6 . Here, the spatial distances are those among cooper atoms in the active site of tyrosinase, oxygen atoms in hydroxyl groups and/or nitrogen atoms $\left(\mathrm{N}_{1}-\mathrm{N}_{3}\right)$ of substrate molecules which make possible form coordinate bonds. The $\mathrm{ClogP}$ values of substrate molecules were in the range of 0.380 to 4.106 which were higher than those of kojic acid. The ClogP concept of skin sensitization is a critical issue in the development of cosmetic products that depends on the bioavailability. According to the literature, ${ }^{31}$ human in vitro skin absorption experiments with a series of unrelated chemicals have determined that the optimum $\mathrm{C} \log \mathrm{P}$ for maximum absorption is approximately 2 , with rapid loss of absorption at $\log \mathrm{P}$ value either side.
Therefore, ClogP values of thiosemicarbazone analogues (131) were roughly estimated in the range of optimum. The highest scored docking compound was $\mathrm{R}_{1}=4$-isopropylphenyl $\& \mathrm{R}_{2}=$ methyl substituent (7; DS $=7.14$ ). It is predicted that most of the substrate molecules would be good to dock with the active site of receptor from the range of crash scores $(-0.34 \sim-1.77)$.

The Inhibiting Mechanism. To illustrate detailed interaction mechanism, the docking pose of the highest scored compound (7) and its H-bonding condition around the active site of tyrosinase are depicted in Figure 5. Spatial distance between the nitrogen atom of $\mathrm{N}(2) \mathrm{H}$ group in substrate molecules and copper atoms in the active site of receptor was $3.46 \AA$ (not shown). A H-bonding analysis indicated to form two $\mathrm{H}$-bonds by reacting $\mathrm{H}$ atom in the $\mathrm{N}(2) \mathrm{H}$ group of substrate molecules respectively with the nitrogen atom of azomethine group on imidazole ring of residue His194 and the oxygen atom of peroxide- $\mathrm{Cu}$ group (oxy tyrosinase) which consists of two tetragonal $\mathrm{Cu}(\mathrm{II})$ atoms. ${ }^{6 \mathrm{a}, 32}$ From 


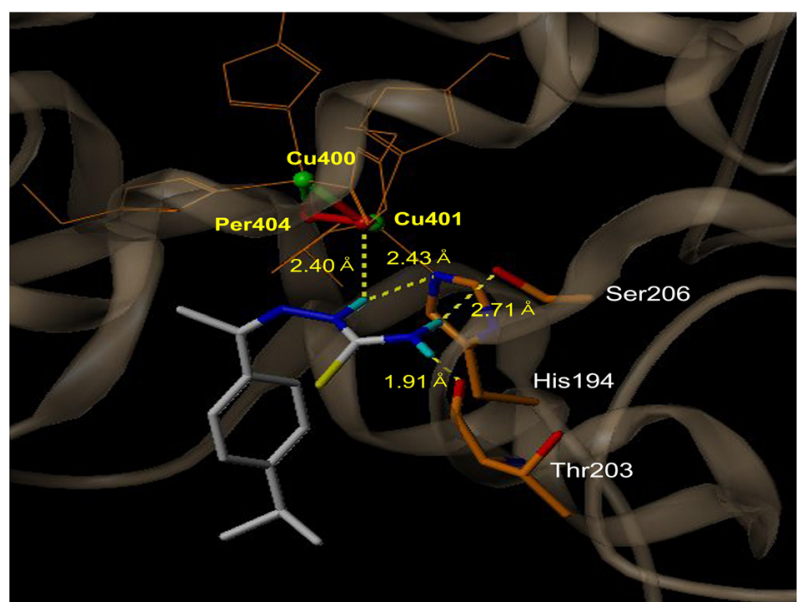

Figure 5. Predicted binding mode and docking pose between the most docking scored substrate molecule $(7 ; \mathrm{DS}=7.14)$ and active site of oxy-form of tyrosinase (1WX2). Hydrogen bonds (yellow dot line) and its distances between two atom pairs are displayed. The $\alpha$-helix were shown as helix or cylinders, while $\beta$-sheets were shown as arrows and the loop regions as tubes.

these two H-bonds, the distance of one bond is $2.40 \AA$ and that of the other is $2.43 \AA$. To make another H-bonds, $\mathrm{H}$ atom of $\left.\mathrm{N}_{3} 3\right)_{2}$ group in substrate molecules react respectively with hydroxyl oxygen of residue Ser206 and carbonyl oxygen atom of residue Thr203. From these two H-bonds, the distance of one bond is $2.71 \AA$ and that of the other is $1.91 \AA$. Therefore, in case of compound (7), four H-bonds between substrate molecules and amino acid residues in the active site of tyrosinase were formed to make a stable substrate-receptor complex compound. These results were in accord with the fact that the inhibitory activity with the optimized CoMSIA 2 model depends on the H-bond acceptor favored field $(36.5 \%)$ of thiosemicarbazone analogues (131) (see Fig. 4). Four $\pi-\pi$ stacking sites with the interaction between $\mathrm{R}_{1}$ group in substrate molecules and the phenyl group of amino acid residue His194 were found. As mentioned above, from these docked conformations in this study, all docked ligands had a H-bonding interaction between $\mathrm{H}$ bond donors in the substrate molecules and H-bond acceptors in amino acid residues within the distance of $3.5 \AA$ between substrate ligands and amino acid residues. The sulfur and nitrogen atoms in the substrate molecules could exhibit strong affinity for copper atom in the active site of tyrosinase. It is supposed that these complexes would be formed between the substrate molecules and tyrosinase. ${ }^{11 \mathrm{~d}}$ From the molecular docking with the substrate molecules and tyrosinse in our work, the H-bonds were created, but the coordinate bond between substrate molecules and copper atoms would not formed because the spatial distance between sulfure (and/or nitrogen) atoms in substrate molecules and copper atoms in the active site of tyrosinase is too long to bond. Therefore, it is supposed that the inhibitory activation of the substrate molecules against tyrosinase would take place via competitive inhibition such as azelaic acid because the acid would not form the complexes as a chelate.
Acknowledgments. This work was supported by Corsvision Inc. and the National Research Foundation (NRF) grant (No. 2010-0062913) funded by the Korea Government (MEST).

\section{References}

1. Chase, M. R.; Raina, K.; Bruno, J.; Sugumaran, M. Insect. Biochem. Molec. 2000, 30, 953.

2. (a) Chen, Q. X.; Liu, X. D.; Huang, H. Biochemistry-Moscow 2003, 68, 644. (b) Olivares, C.; Cervantes, C. J.; Lozano, J. A.; Solano, F.; Garcia-Borron, J. C. Biochem. J. 2001, 354, 131.

3. Sptitz, R. A.; Hearing, V. J., Jr. Adv. Hum. Genet. 1994, 22, 1.

4. Martinez, M. V.; Whitaker, J. R. Trends Food Sci. Technol. 1995, $6,195$.

5. (a) Matoba, Y.; Kumagai, T.; Yamamoto, A.; Yoshitsu, H.; Sugiyama, M. J. Biol. Chem. 2006, 281, 8981. (b) Jackman, M. O.; Hajnal, A.; Lerch, K. Biochem. J. 1991, 274, 707.

6. (a) Kim, Y. J.; Uyama, H. Cell. Mol. Life Sci. 2005, 62, 1707. (b) Wilcox, D. E.; Porras, A. G.; Hwang, Y. T.; Lerch, K.; Winkler, M. E.; Solomon, E. I. J. Am. Chem. Soc. 1985, 107, 4015. (c) Sanjust, E.; Cecchini, G.; Sollai, F.; Curreli, N.; Mescigno, A. Arch. Biochem. Biophys. 2003, 412, 272.

7. Khan, K. M.; Maharvi, G. M.; Khan, M. T. H.; Shaikh, A. J.; Perveen, S.; Begaum, S.; Choudhary, M. I. Bioorg. Med. Chem. 2006, 14, 344 .

8. Parvez, S.; Kang, M.; Chung, H. S.; Bae, H. Phytother. Res. 2007, 21,805 .

9. Khan, M. T. H. Pure Appl. Chem. 2007, 79, 2277.

10. Khan, M. T. H. Topics Heterocyclic Chem. 2007, 9, 119.

11. (a) Xue, C. B.; Zhang, L.; Luo, W. C.; Xie, X. Y.; Jiang, L.; Xiao, T. Bioorg. Med. Chem. 2007, 15, 2006. (b) Pasha, F. A.; Muddassar, M.; Beg, Y.; Cho, S. J. Chem. Biol. Drug. Des. 2008, 71, 483. (c) Yi, W.; Cao, R. H.; Chen, Z. Y.; Yu, L.; Ma, L.; Song, H. C. Chem. Pharm. Bull. 2009, 57, 1273. (d) Liu, J.; Yi, W.; Wan, Y.; Ma, L.; Song, H. Bioorg. Med. Chem. 2008, 16, 1096. (e) Yi, W.; Cao, R.; Chen, Z.; Yu, L.; Wen, H.; Yan, Q.; Ma, L.; Song, H. Chem. Pharm. Bull. 2010, 58, 752 .

12. Xue, C. B.; Luo, W. C.; Ding, Q.; Liu, S. Z.; Gao, X. X. J. Comput. Aided Mol. Des. 2008, 22, 290.

13. Chung, S. W.; Ha, Y. M.; Kim, Y. J.; Song, S.; Lee, H.; Suh, H.; Chung, H. Y. Arch. Pharm. Res. 2009, 32, 289.

14. Chen, Y. R.; Chiou, R. Y.; Lin, T. Y.; Huang, C. P.; Tang, W. C.; Chen, S. T.; Lin, S. B. J. Agri. Food Chem. 2009, 57, 2200.

15. Sung, J. H.; Park, S. H.; Seo, D. H.; Lee, J. H.; Hong, S. W.; Hong, S. S. Biosci. Biotechol. Biochem. 2009, 73, 552.

16. Sung, N. D.; Jung, H. S.; Kim, S. J. J. Soc. Cosmet. Scientists Korea 2004, 30, 491 .

17. Sung, N. D.; Chung, Y. H.; Jang, S. C.; Kim, S. J. J. Appl. Biol. Chem. 2007, 50, 52 .

18. Kim, S. J.; Kim, S. G.; Sung, N. D. J. Soc. Cosmet. Scientists Korea 2008, 34, 109.

19. (a) Akamatsu, M. Curr. Topics Med. Chem. 2002, 2, 1381. (b) Cramer, R. D., III.; Patterson, D. E.; Bunce, J. E. J. Am. Chem. Soc. 1988, 110, 5959. (c) Klebe, G.; Abraham, U.; Mietzner, T. J. Med. Chem. 1994, 37, 4130.

20. Tripos Inc., Sybyl molecular modeling and QSAR software on CD-Rom, (Ver.8.1.1) Theory and manual., St. Louis, Missouri. 2008.

21. (a) Soung, M. G.; Kim, J. H.; Kwon, B. M.; Sung, N. D. Bull. Korean Chem. Soc. 2010, 31, 1335. (b) Soung, M. G.; Park, K. Y.; Sung, N. D. Bull. Korean Chem. Soc. 2010, 31, 1469. (c) Soung, M. G.; Kil, M. J.; Sung, N. D. Bull. Korean Chem. Soc. 2009, 30, 2749.

22. Kerr, R. Biophys. J. 1994, 67, 1501.

23. Cramer, R. D.; Bunce, J. D.; Patterson, D. E. Quant. Struct. Act. 
Relat. 1988, 7, 18.

24. Clark, R. D.; Fox, P. C. J. Comput. -Aided. Mol. Des. 2004, 18, 563.

25. Quian, L.; Brian, M.; Karl, S.; Julian, S. J. Med. Chem. 2007, 50, 5392.

26. (a) Jain, A. N. J. Med. Chem. 2003, 46, 499. (b) Patrick, A. H.; Jonathan, B. C.; John, O. T. J. Chem. Inf. Model. 2008, 48, 1602.

27. Jain, A. N. J. Comp. -Aided Mole. Des. 1996, 10, 427.

28. (a) Clark, R. D.; Fox, P. C. J. Comput. -Aided. Mol. Des. 2003, 17, 1. (b) Clark, R. D.; Sprous, D. G.; Leonard, J. M. Validating Models Based on Large Data Sets; Prous Science: Barcelona, 2001; 475.

29. Kahn, V., Ben-Shalom, N.; Zakin, V. J. Agric. Food Chem. 1997,
$45,4460$.

30. Briganti, S.; Camera, E.; Picardo, M. Pigment. Cell. Res. 2003, $16,101$.

31. (a) Smith, C. M.; Hotchkiss, S. A. M. Allergic Contact Dermatitis Chemical and Metabolic Mechanisms; Taylor and Francis: London, 2001. (b) Jowsey, I. R; Basketter, D. A.; Westmoreland, C.; Kimber, I. A. J. Appl. Toxicol. 2006, 6, 341. (c) Natsch, A.; Wmter, R.; Ellis, G. Toxicol. Sci. 2009, 107, 106.

32. (a) Himmelwright, R. S.; Eickman, N. C.; Lubein, C. D.; Solomon E. I.; Lerch, K. J. Am. Chem. Soc. 1980, 102, 2563. (b) Kim, Y. J.; Chung, J. E.; Kurisawa, M.; Uyama, H.; Kobayashi, S. Biomacromol. 2004, 5, 474 . 